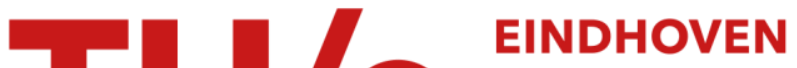 UNIVERSITY OF TECHNOLOGY
}

\section{Mechanical failure of cemented femoral total hip replacement}

Citation for published version (APA):

Verdonschot, N. J. J., \& Huiskes, R. (1995). Mechanical failure of cemented femoral total hip replacement. In R. Kossowsky, \& N. Kossowsky (Eds.), Advances in materials science and implant orthopedic surgery (pp. 135148). (NATO ASI Series : Series E, Applied sciences; Vol. 294). Springer.

Document status and date:

Published: 01/01/1995

\section{Document Version:}

Publisher's PDF, also known as Version of Record (includes final page, issue and volume numbers)

\section{Please check the document version of this publication:}

- A submitted manuscript is the version of the article upon submission and before peer-review. There can be important differences between the submitted version and the official published version of record. People interested in the research are advised to contact the author for the final version of the publication, or visit the $\mathrm{DOI}$ to the publisher's website.

- The final author version and the galley proof are versions of the publication after peer review.

- The final published version features the final layout of the paper including the volume, issue and page numbers.

Link to publication

\section{General rights}

Copyright and moral rights for the publications made accessible in the public portal are retained by the authors and/or other copyright owners and it is a condition of accessing publications that users recognise and abide by the legal requirements associated with these rights.

- Users may download and print one copy of any publication from the public portal for the purpose of private study or research.

- You may not further distribute the material or use it for any profit-making activity or commercial gain

- You may freely distribute the URL identifying the publication in the public portal.

If the publication is distributed under the terms of Article 25fa of the Dutch Copyright Act, indicated by the "Taverne" license above, please follow below link for the End User Agreement:

www.tue.nl/taverne

Take down policy

If you believe that this document breaches copyright please contact us at:

openaccess@tue.nl

providing details and we will investigate your claim. 


\title{
Mechanical failure of cemented femoral total hip replacement
}

\author{
Nico Verdonschot and Rik Huiskes \\ Biomechanics Section, Inst. Orthopaedics, University of Nijmegen \\ 6500 HB Nijmegen, The Netherlands.
}

\section{Introduction}

Owing to the large number of total hip replacements (THR) included (over 90,000 ), the Swedish multi-center studies have demonstrated the possibility to investigate the factors which influence the success rate of total hip replacements [15]. In that study it was found that the failure rates of cemented THR are significantly affected by prosthetic design factors. They could also demonstrate that improved surgical and cementing techniques improved the prospects of THR. These findings can be considered as the fruits of the efforts of the orthopaedic community. However, as the incidence of primary THR is increasing dramatically, and the success rates for (re)revised THR's are significantly lower than for the primary ones, major problems for the orthopaedic surgeon lay ahead.

In the last few decades, laboratory experiments, animal studies, analytical studies, clinical trials, and retrieval analyses have been used to improve our understanding concerning mechanisms involved in the failure of cemented THR. As demonstrated by the Swedish study, we have succeeded in improving the quality of hip implants. However, at this point in time, thirty years after the introduction of acrylic cement, the design parameters determinative for a successful cemented THR are still unclear, and the innovation process of THR seems to have failed to some extent [9].

In this paper an overview of what we do know about failure of cemented THR is given. It may serve as an introduction in biomechanical aspects that are involved in failure of cemented THR. In the first chapter, the mechanical factors affecting the failure of cement femoral THR's are discussed. In the second chapter, some practical guidelines are given to prevent or postpone mechanical failure of cemented THR.

$R$. Kossowsky and N. Kossovsky (eds.), Advances in Materials Science and Implant Orthopedic Surgery, 135-148. (c) 1995 Kluwer Academic Publishers. Printed in the Netherlands. 
Factors which affect mechanical failure of femoral THR's.

When a prosthetic stem is loaded, it transfers the joint load to the bone. Near the prosthetic head, where the load is introduced, the prosthesis carries the hip joint force, whereas in the diaphysial area, distal to the prosthesis, the bone carries all the load. In between these regions, the load is transferred from stem to bone. How this is achieved is called the 'load-transfer mechanism' [5]. Load-transfer is governed by stresses generated in the materials and at their connections. The likelihood of mechanical failure of the structure is dominated by these stress levels relative to their strengths.

The stress levels in the structure can be effectively analyzed by using the Finite Element (FE) method. With this method it is possible to calculate mechanical quantities (stresses, strains, motions, etc.) at every location in the structure. The effects of certain (design) parameters can be calculated by varying this parameter while keeping the others constant.

The stress patterns in the structure depend on four aspects (figure 1). They include: (i) the magnitudes and orientations of the external Ioads, (ii) the properties of the materials, (iii) the geometry, and (iv) and the connections between the separate substructures; the interfaces.

In the next paragraphs, the effects of these four aspects on the probability of mechanical failure are discussed.

\section{(i) External loads}

The external loads are predominantly governed by patient related factors. Obviously, higher load levels lead to higher stress levels and increase the probability of implant failure.

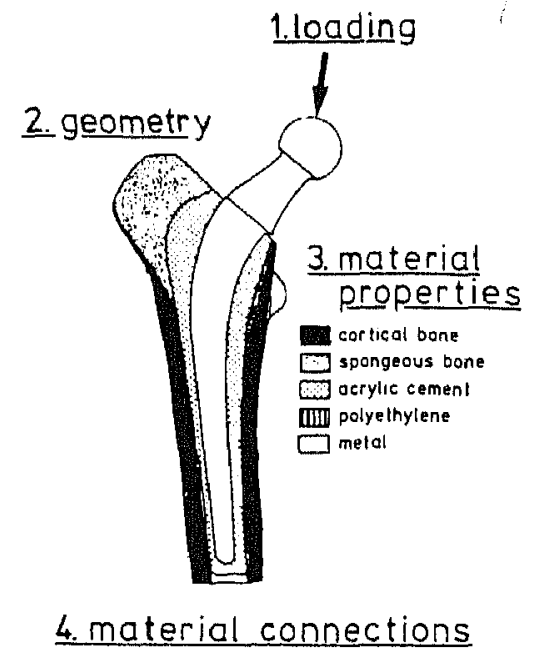

Figure 1. The stress patterns in the bone/prosthesis structure depend on four aspects. This is probably why shorter prosthetic endurance limits have been found with patients of heavy weight or those who are relatively young (and more active) [15]. Not only the magnitude of the joint force is of importance, but also its direction. Of particular interest is the so-called out-of-plane loading component of the joint force which applies a torsional load on the implant. These loading conditions are generated in activities such as stair climbing or rising from a chair. Harrigan et al. [3] demonstrated that it is this kind of loading mode that causes the highest stresses in the structure. 


\section{(ii) Materials}

Basically, three materials are used in a femoral cemented THR: the stem metal, bone, and acrylic cement. All three materials play a role in the stress levels occurring in the structure, and their influences interact with each other. Figure 2 schematically shows how a natural bone bends when it is loaded with a bending moment.

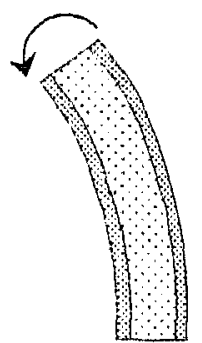

a

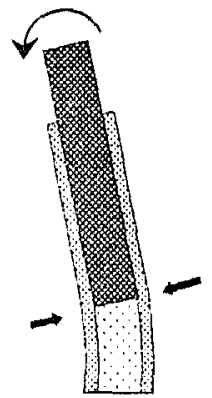

b

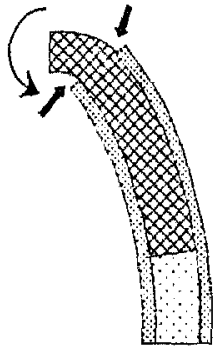

c

Figure 2. (a) The 'natural' bending deformation of a long bone. (b) Insertion of a relatively stiff prosthesis restrains the deformation around the prosthesis. Especially a the distal end of the prosthesis (arrows), the bone will move relative to the prosthesis as a result of the dynamic loading. (c) When a relatively flexible prosthesis is inserted, the deformation of the prosthesis is restrained, rather than the deformation of the bone. Especially at the proximal end (arrows), the prosthesis will move relative to the bone.

When the implant is much stiffer than the bone, the bending predominantly occurs in the tip region. This causes high interface stresses between the stem and bone in this region, and low stresses at the proximal side. Implanting a stem which is more flexible, the opposite occurs. High proximal interface stresses are generated.

Figure 3 shows the same phenomenon, but in a more realistic model. It shows the tensile and compressive stresses at the interface for a very stiff cobalt-chromium stem, a relatively stiff titanium stem, and a relatively

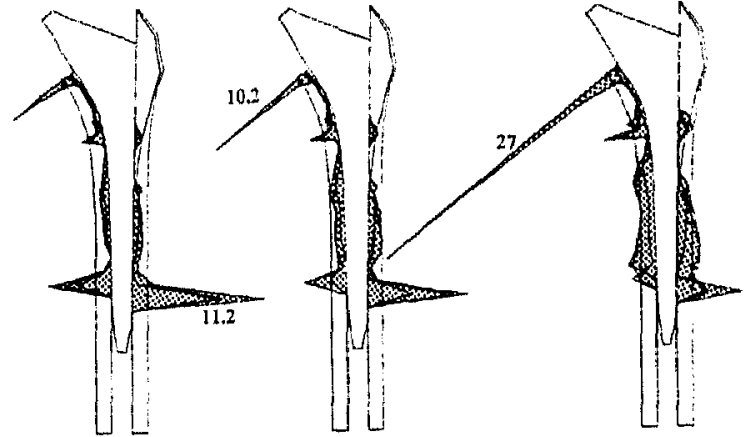

Figure 3. Normal stresses at the bone implant interface for a CoCrMo, titanium, and 'iso-elastic prosthesis. (Peak stresses are indicated in the figure). 
flexible 'iso-elastic' stem. ('Iso-elastic' indicates that the stiffness of the prosthetic material is similar to that of bone itself). Proximal stresses are much higher for the flexible stem. Cemented stems usually have smaller dimensions than uncemented ones as a layer of cement between the implant and bone is apparent. This makes the cemented stems more flexible and this will result in a high amount of proximal load-transfer. For this reason, cemented stems are generally made out of stiff materials, such a cobaltchromium alloys or stainless steel.

Contrarily to the prosthetic material, the mechanical properties of acrylic cement may change considerably in the course of time. It is well known that due to an aging process, plastic materials (including acrylic bone cement) stiffen in time. However, the material is also affected by the stress levels to which it is exposed. The cement material can locally fracture or it can creep [17]. The latter phenomenon can be described as a timedependent deformation of the material under constant loading conditions. Fracture and creep are both time-dependent processes, and an investigation of these phenomena with FE techniques requires a time-dependent simulation of the processes.

In the simulation of cement fracturing, the stresses in the cement are calculated by the $\mathrm{FE}$ routine and compared with fatigue strength data of bone cement. These damage analyses investigate the locations where fracture of the cement mantle is initiated and how it progresses [16]. An example is shown in figure 4 where the damaged cement

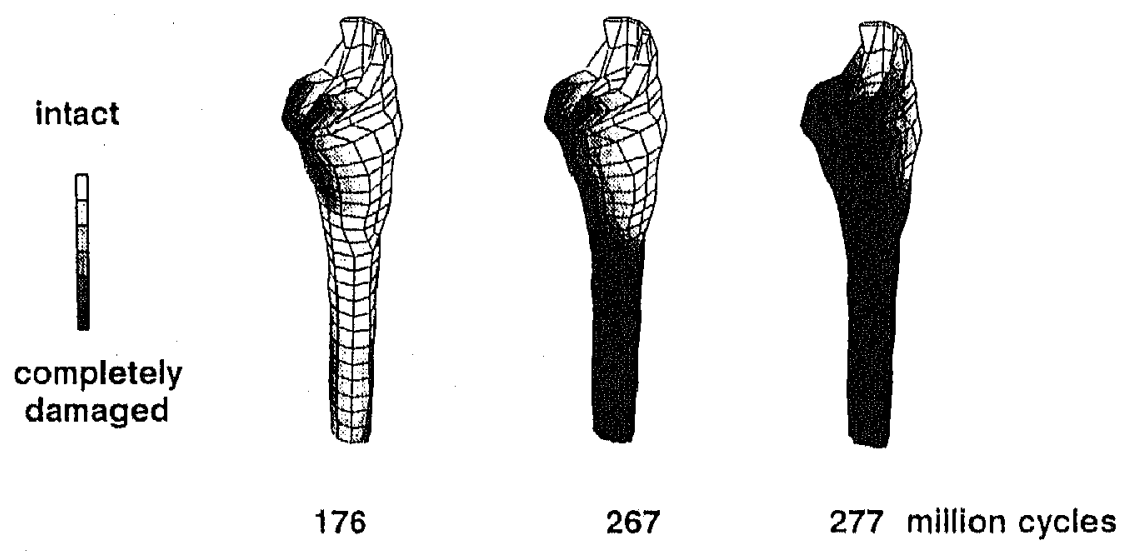

Figure 4. Damage in the cemenl mantle at various stages in the damage process, assuming a perfectly bonded stem/cement interface.

sites are shown in various stages of the damage process. Cement fracture was initiated in the tip region and at the proximal/medial region. These damaged zones seemed to grow until the whole cement mantle was damaged. It appears that the process of damage 
accumulation in the cement mantle can be divided in three stages. In the first stage, the damage growth was rather slow, and the overall stiffness of the cement mantle was hardly affected. When more material became damaged, the mechanical integrity of the cement was reduced, which increased the damage rate (stage 2). In the final stage the cement mantle had lost its capacity to sustain any load and fractured completely after about $2.7 * 10^{8}$ loading cycles. Comparing this number with daily activities assuming a number of loading cycles of about 1 million per year (about 4 kilometers walking each day), the stem would function for about 270 years. This survival time already indicates that the results should only be interpreted in the right perspective. However, these analyses enhance our understanding about the factors involved in failure of cemented THR's. In addition they provide the possibility to analyze, on a qualitative basis, the effects of design parameters on the mechanical survival time of the cement mantle.

The effects of creep of bone cement around a hip stem on the stress patterns can not easily be investigated in an in-vivo or laboratory experiment, but quite effectively using FE techniques. Figure 5 shows the tensile stress distribution in a part of the cement mantle before and after creep of the bone cement was simulated.

A considerable reduction in stresses occurred after creep. For the whole cement mantle, the

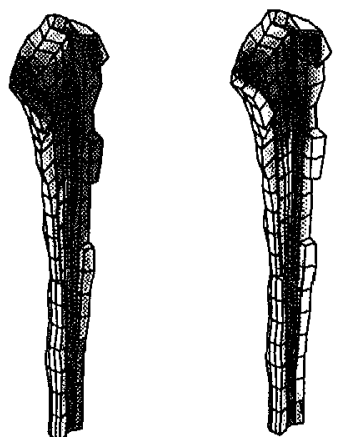

Figure 5. The tensile stress distribution in a part of the cement mantle before (left) and after (right) creep has occurred. Dark areas indicate high stresses. average tensile cement stresses decreased with about 50 percent after 5 million loading cycles. Therefore, it can be concluded that creep properties of bone cement have a considerable relaxating effect on the cement stresses. This will have a positive effect on the mechanical lifetime of the replacement.

\section{(iii) Geometry}

The geometry of the structure is affected by implant, patient and surgical factors. There are numerous types of implants on the market with all kinds of shapes. Using FE techniques, it is possible to compare various designs with different shapes, keeping the other variables constant [8]. As an example of this method, figure 6 shows the range of stresses generated in the proximal cement for four types of prostheses. Calculating the stress ranges is easier than the interpretation of these values.

Peak stress values can give an indication about the probability of cement failure. However, when only a very small volume of bone cement is exposed to this stress level,

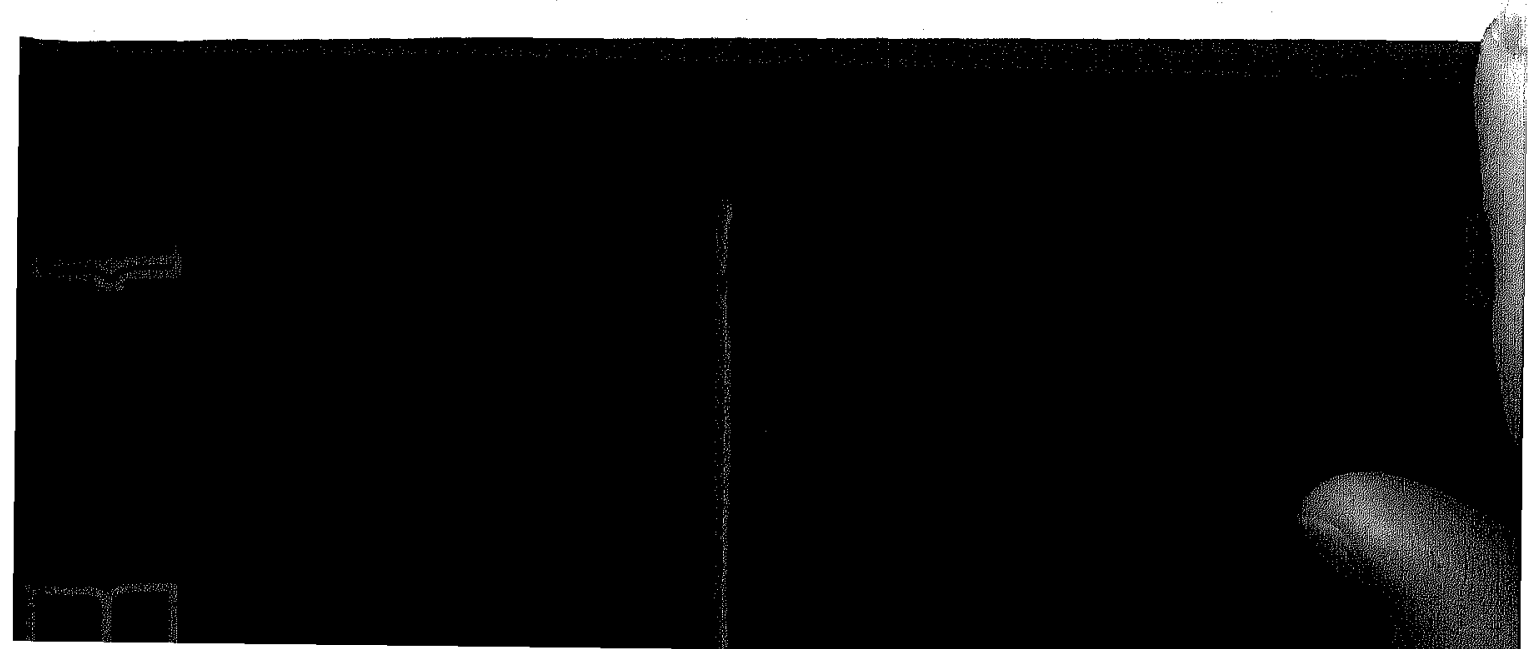


cement failure may be less probable than when a larger volume is exposed to lower stress level.

The shape of the prosthesis is three-dimensional. However, the effects of the contours of the stems in the transverse plane (rectangular, round, sharp-edged, etc.) have been underestimated in the past. From retrieval studies,

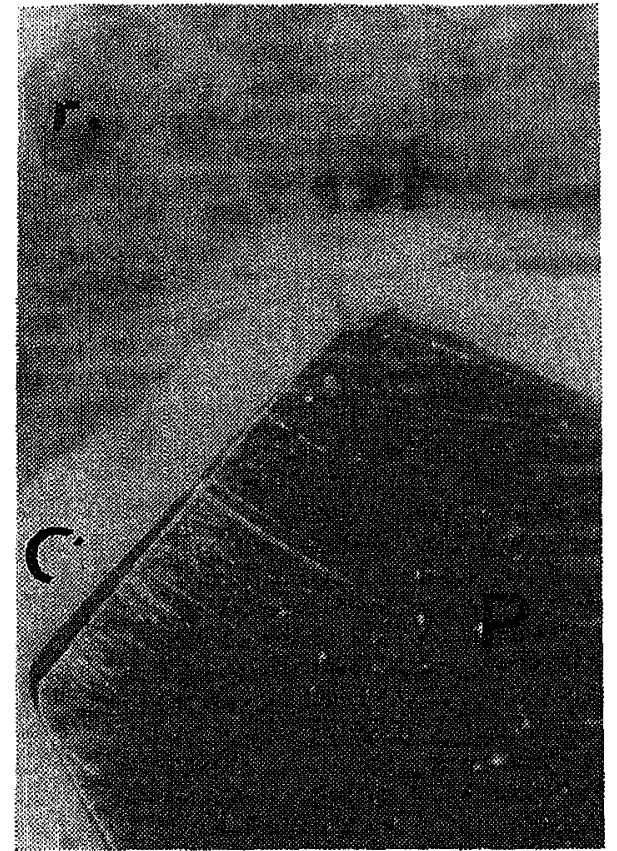

Figure 7. A transverse section of a post-mortem retrieved specimen. The stem has debonded from the cement mantle. The sharp corners of the prosthetic contour have led to cement fractures.

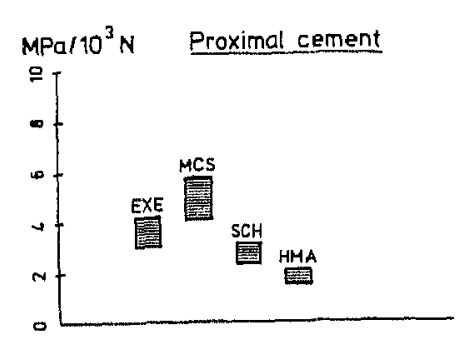

Figure 6. Proximal peak stresses in the cement mantle produced around the Exeter stem, the Muller Curved stem, the Scandinavian Hip, and the Howmedica Precision hip.

we know that the contour of the stem in this plane can have large consequences on the survival of cement femoral hip implants [12]. Figure 7 shows a cross section of a post-mortem retrieved specimen. It appears that the cement has fractured at the corner of the prosthesis. These cracks appear at those locations where the cement mantle is thin. The figure also shows that the prosthesis has debonded from the cement and rotated in the cement mantle. This phenomenon is caused by the out-ofplane loading of the prosthesis.

One step further in the analysis of loadtransfer in cemented THR is the combination of the FE method with mathematical optimization techniques [6]. Starting with a traditional stem shape, cement stresses are calculated. Highest stresses are found in the proximal and in the tip region. Subsequently, the prosthetic shape is modified in such a way that cement stresses are minimized (figure 8 ), and the probability of failure is reduced.

The bone geometry (a patient factor) also affects the load-transfer in the structure. If a femur has a thick cortex, it will be relatively stiff. As shown in the preceding paragraph, a stiff cortex (or a relatively flexible stem) results in more proximal loadtransfer. 


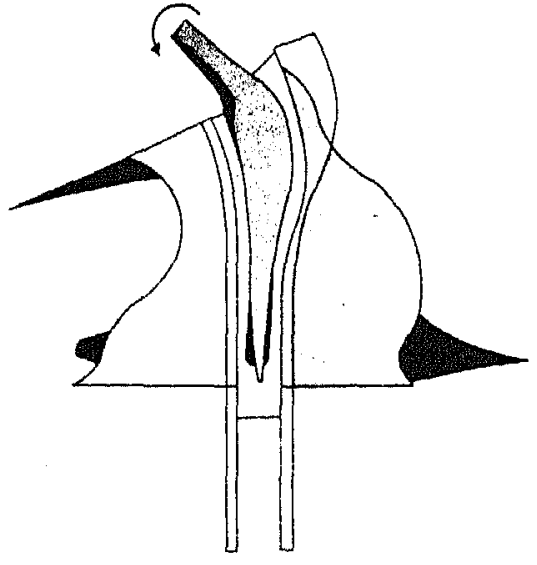

Figure 8. Using optimization routines, the elastic energy in the cement at the cement/bone interface can be optimized. Dark: prior to optimization; light: after optimization.
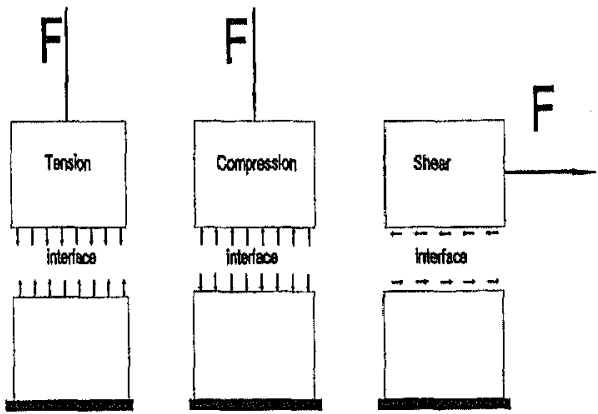

inderfece

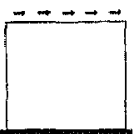

Figure 9: Interface stresses can be oriented perpendicular to the interface (compressive or tensile), or parallel to it (shear).

\section{(iv) Interfaces}

Stresses are transferred from one material to the other by stresses at the interface between these two materials.These stresses can benormal (compressive, tensile) and/or shear stresses. Normal stresses are stresses oriented perpendicular to the surface, while shear stresses occur parallel to the surface (see figure 9).

Normal stresses can either be tensile (when there is a 'pulling force' between the two materials) or compressive (the materials are pressed against each other).

In a structure of a cemented hip stem, two interfaces can be distinguished. The one between the stem and the cement and the one between the cement and the bone. It appears that the characteristics of these interfaces are the most important factors determining the stress distributions, and therefore the probability of mechanical failure of femoral THR's [7]. First, the effects of the stem/cement interface characteristics are discussed, after which the effects of the cement/bone interface are addressed.

Considering the implant/cement interface, two types of prosthesis available on the orthopaedic market can be identified. The first type has a stem which is firmly fixed to the cement by means of a pre-coating or a rough stem surface. This type of stem can transfer normal, tensile and shear stresses at the interface. The second type has a very smooth, highly polished surface finish and does not bond to the cement mantle. Therefore, tensile stresses can not be transferred at the interface, and shear stresses can only occur when there is friction occurring between the two surfaces. 
The difference in load-transfer between these two types of prostheses (bonded vs unbonded) can be demonstrated by considering a taper which is pushed into a surrounding material. In figure 10 , the interface stresses are shown in case of a bonded

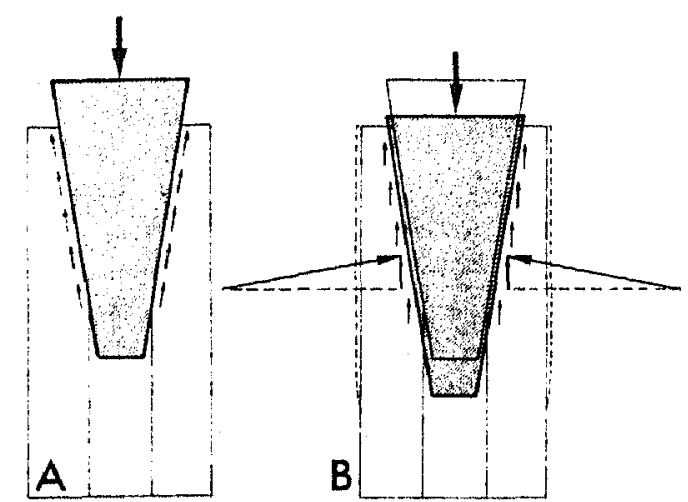

Figure 10. Load transfer from a cone pushed into a counterpart, assuming a bonded (A) or unbonded (B) interface. High compressive stresses in the unbonded case expand the surrounding material. and an unbonded taper.

In both cases, the force applied to the taper of the prosthesis has to be transferred at the interface to the surrounding material. In case of the unbonded prosthesis, load can only be transferred by means of compressive stresses (if there is no friction), whereas in the case of a bonded prosthesis, additional shear stresses can occur. The total sum of the axial components of the interface stresses is equal to the external load applied to the taper. When the taper is bonded, shear stresses are relatively important. In case of an unbonded taper, the axial component of the compressive stresses is small, indicating that high compressive stresses are necessary to compensate for the axial force applied to the taper. Obviously, the axial component of the various stress components are directly related to the taper angle. Reducing this angle results in a smaller axial component of the compressive stresses, which means that higher compressive stresses are required to compensate for the external force. The assumptions of a fully bonded or a fully unbonded prosthesis without any friction are two extreme situations. The reality is somewhere between these two extremes, because of friction.

Using FE techniques the effects of these interface conditions on the stress levels occurring in the cement mantle can be investigated. It appears that, indeed, the stress distributions depend largely on these conditions (figure 11).

The bonded stem showed stress concentrations at the proximal and the distal side of the prosthesis. In addition, the unbonded stems generated an overall stress increase in the cement mantle with stress peaks at the lateral corners of the prosthesis. The bonded stem generates stresses that are relatively low. The unbonded, frictionless prosthesis subsides in the cement mantle and stretches it. This results in high stresses around the stem. When friction is assumed, the stem subsides less and stresses occur predominantly at the corners of the stem. This means that the smallest chance for mechanical failure is caused by the prosthesis which is fully bonded to the cement mantle. The unbonded stem, without friction at the stem/cement interface, has the highest failure probability. 

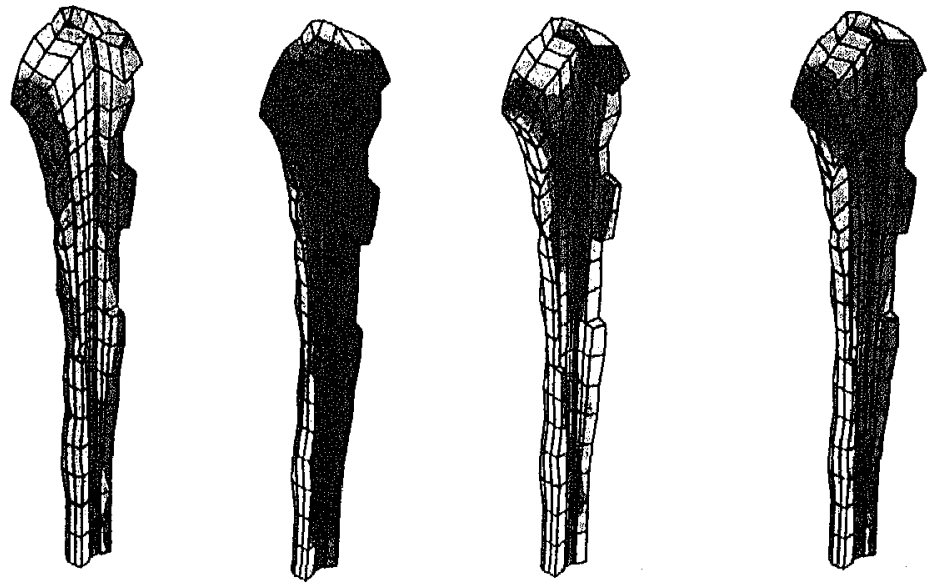

Figure 11. The effect of stem/cement bonding characteristics on the tensile stress distribution in a part of the cement mantle. From left to right: a bonded, an umbonded frictionless, an unbonded low friction, and an unbonded high friction interface.

However, in reality, friction at the interface occurs and cement stresses are significantly lower, leading to a failure probability which may only be slightly higher as compared to the fully bonded stem.

In the above, it was assumed that the implant was either unbonded (smooth, polished implant) or completely bonded (pre-coated or rough implant). However, a number of studies have indicated that cemented femoral stems debond from the cement mantle after some time [2,12]. Around most debonded areas, a very thin layer of soft tissue is present. In our own retrieval studies, we also frequently found that the prosthesis had debonded from its cement mantle. Figure 12 shows a prosthesis partly covered with a layer of soft tissue. This demonstrates that debonding of the stem had occurred long before the patient died. The mechanical effects of gradual debonding of the stem are still unclear. Does partial debonding of the stem/cement interface lead to an increase in interface stresses, which leads to an acceleration of the debonding process, or is it a rather stable process? Does (partial) debonding lead to an increase of stresses in the cement mantle, and therefore does it induce failure of the cement mantle? In other words: has the implantation failed once debonding has started? To answer these questions, we performed a simulation of the debonding process of a cemented femoral stem. At the stem/cement interface, shear, tensile and compressive interface stresses can occur. Failure of the stem/cement interface was assumed at locations with a high values for the shear and/or tensile stress component.

Using this method, the process of gradual debonding of the prosthesis was simulated without consideration of the actual time axis of the debonding process. Debonding 


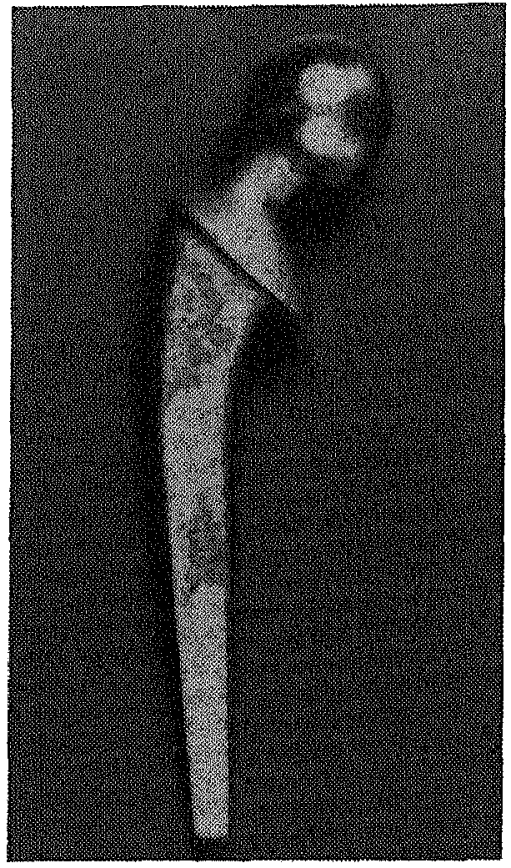

Figure 12. A post-mortem retrieved stem extracted from its cement mantle is partly covered with a layer of sofi-tissue. started in the tip region, but was directly followed by debonding in the proximal, medial-anterior region. The proxi$\mathrm{mal} /$ lateral region was the last region to become unbonded. Figure 13 illustrates this by showing the state of debonding after different percentages of debonded area for the frictional case. In their retrieval study, Jasty et al. [12] concluded that long-term failure of the fixation of cemented femoral components were primarily of mechanical origin, starting with debonding at the stem/cement interface, and propagating in the cement mantle. They found stem/cement debonding in all specimens even if the prosthesis had been in place for only two weeks! This indicates that debonding usually occurs early after surgery. Locations where debonding most frequently occurred were the proximal/anterior side and in the tip region. This confirms the results as found in the analyses where debonding originated in

these regions. The stresses at the interface remained at a rather constant level as debonding proceeded. In case these stresses would increase with more debonded area, the process would be an unstable one. This would indicate that when only a small portion of the interface would be debonded, an accelerated debonding process would be initiated. However, in this study, the interface stresses remained at a rather constant level. Hence, the loosening process is a rather stable one. This finding implies that although debonding of a part of the prosthesis may occur relatively soon after implantation, this would not have to cause an impetuous failure of the interface as a whole. Gradual debonding of the prosthesis had its effect on the stresses occurring in the bone, the cement, at the stem/cement interface and at the cement/bone interface. The maximal tensile stress in the cement mantle slowly increased as debonding of the stem/cement interface proceeded. For this reason it can be expected that the probability of mechanical failure slowly increases when the stem gradually debonds form the cement mantle.

The effects of the cement/bone interface characteristics on the probability of failure is quite clear. This interface should be as strongly bonded as possible. In the case 
that the interface is not firmly bonded, but interface micro- motions occur, adverse bone reactions can be expected. In that case a layer of soft-tissue often develops, thereby reducing the stiffness of the living tissue, and increasing the amount of micro-motion at the interface. Due to the cyclic load of the prosthesis a pumping mechanism may be activated that transports foreign body particles to the interface. This, again, accelerates soft-tissue formation at the interface.

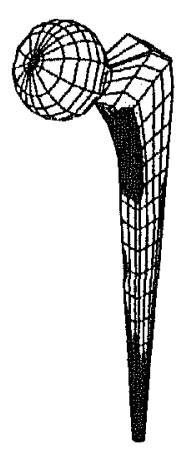

25 percent unbonded

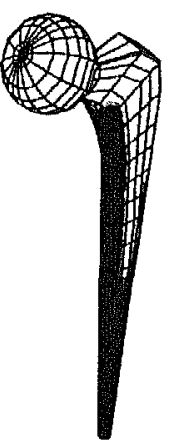

50 percent unbonded

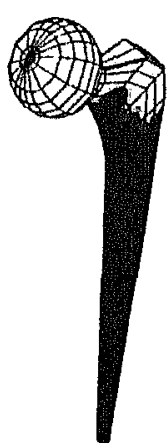

75 percent unbonded

Figure 13. Debonded stem/cement sites (dark) at various stages in the debonding process.

The prevention of mechanical failure

As indicated in the preceding chapter, failure of cemented THR is affected by loading conditions, properties of the materials, geometries, and interface conditions. All these aspects are influenced by patient, surgical and implant related factors. Mechanical failure can be prevented or postponed when these factors are optimized.

One of the most important patient related factors is the load applied to the structure. The external loads can be altered by the surgeon by altering the placement of the stem or by changing the neck length of the implant. A stem implanted in valgus, or a shorter prosthetic neck length will reduce the lever arm of the prosthetic load and hereby it reduces the bending moment acting on the structure. However, it also reduces the leverarm of the abductor muscles. Therefore, these muscles must generate more load to generate the same abduction moment. This causes an increase in prosthetic load and bending moment, and the total reduction in bending moment has disappeared. In addition, muscle coordinating and proprioseptic problems can also be expected as a result of anatomical changes. Therefore, it should be emphasized that the placement of the stem and the choice of neck length should be such that the locations of load application are restored as well as possible.

Patients should be familiar with the fact that the endurance of their implant depends on the amount of loading produced in the hip joint. Therefore, they should be instructed to limit the number of loading cycles and to minimize activities such as stair-climbing or rising from a chair.

The materials used in a THR are governed by patient, implant and surgical factors. The properties of the bone obviously depend on patient factors, and can hardly be influenced 
to enhance the survival probability of the THR. The introduction of new materials for the prosthetic stem has led to an almost negligible percentage of stem breakage. At present, a lot of research is done to determine how the best cement properties are obtained. The cement material properties are not only affected by the type of cement, but also by surgical factors. The mechanical properties of bone cement obtained with advanced mixing procedures (vacuum or centrifugation) have shown to be superior as compared to those obtained with hand mixed procedures [1]. Lavage of the femoral canal reduces the amount of contaminations in the bone cement and therefore increases the strength of the material.

The geometry of the cement mantle plays a key role in the endurance of cemented THR's. It is of utmost importance that the cement mantle is complete. To secure an intact cement mantle even when the cement is locally porous, the mantle should have a minimal thickness of about 2-3 mm. If it is incomplete, the stem can contact the bone bed to provoke bone lysis $[11,14]$. The best way to obtain an intact cement mantle with contemporary techniques is to use a cement plug, fill the canal retrogradely and use a stem with cement spacers. Inserting a stem without spacers is 'like playing golf in the dark' [10]. The thickness of the cement mantle is also greatly served by correct sizing and placement of the implant. To optimize these factors, it is strongly suggested to use templates in the pre-planning procedure of the operation. Cement/bone interface conditions are improved by using improved surgical techniques. The interfacial strength depends on the penetration of the cement in the bone bed. A penetration of 2-3 mm seems optimal [13]. A good penetration can be obtained by using a cement plug and pressurizing the cement. Cleaning the bone bed with lavage does not only clean the bone bed from contaminants, so that cement penetration can occur more easily, but it also precools the bone, which reduces the chance of bone necrosis due to polymerization heat [5].

These advanced surgical techniques contribute to an increase in bone cement and cement/bone interfacial strength and therefore reduce the likelihood of mechanical failure of the structure.

The most optimal stem/cement interface conditions are still a matter of debate $[4,14]$. At this point in time, it seems that there are only two options. The first one is to create a firm and lasting bond between the stem and the cement mantle. This may be achieved by pre-coating or roughening the stem surface. The main problem with this type of prosthesis is that it is not certain that the bond will sustain the many years of continuous, dynamic loading. If the bond fails, and micro-motions at the stem/cement interface occur, cement abrasion becomes unavoidable, which ultimately lead to adverse biological reactions at the bone/cement interface. To avoid these problems, a second type of stem has been introduced which will not bond to the cement mantle due to its highly polished surface. As shown in this study, these stems generate stresses in the cement mantle that 
are higher as compared to the bonded types. However, the abrasion of the cement mantle can be expected to be much smaller. At this point in time, it is still unclear which type of stem should be preferred. Only further research can lead to definitive answers about this controversy apparent in the literature $[4,14]$.

In addition to the stem/cement interface characteristics, the shape of the implant significantly affects the mechanical survival time of the implant. However, it still is not clear what the optimal stem geometry is. In general, prostheses should have no sharp edges or ridges that may lead to stress intensities in the cement mantle.

The techniques employed and the designs of THR's are changing rapidly, and the prospects of cemented THR's have been improved [15]. However, not every change has been an improvement and at some points the innovation process has failed [9]. It is the duty of the orthopaedic surgeon to keep informed about the most modern techniques and designs. Information from the designer or manufacturer, clinical data, and results of preclinical tests should be critically assessed. Only when this data is available, the surgeon can reach a responsible decision to change his techniques or use an other type of implant, and improve the survival of cemented THR.

\section{References}

1. Davies J.P., Burke D.W., O'Connor D.O., and Harris W.H. (1987) Comparison of the fatigue characteristics of centrifuged and uncentrifuged Simplex $P$ bone cement, J. of Orthop. Res. Vol. 5, No. 3, p. 366-371.

2. Fornasier V.L., and Cameron H.U. (1976) Their femoral stem/cement interface in hip replacement, Clin. Orthop., 116, 248-253.

3. Harrigan T.P., Kareh J.A., O'Connor D.O., Burke D.W., and Harris W.H. (1992) A finite element study of the initiation of fixation in cemented femoral total hip components, J Orthop. Res.,10, 134-144.

4. Harris W.H. (1992) Is it advantageous to strengthen the cement-metal interface and use a collar for cemented femoral components of total hip replacement? ,Clin. Orthop., 285, 67-72.

5. Huiskes R. (1980) Some fundamental aspects of human joint replacement". Acta Orthop. Scand. suppl 185.

6. Huiskes R., and Boeklagen R. (1989) Mathematical shape optimization of hip prosthesis design, $J$ Biomech. 22, (8/9) 793-804.

7. Huiskes R. (1990.a) The various stress paiterns of press-fit, ingrown, and cemented femoral stems, Clin. Orthop. Rel. Res., 261, 27-38.

8. Huiskes R. (1990.b) Comparative stress patterns in cemented total hip arthroplasty, Orthop. Rel. Sci. 1, 93-108. 
9. Huiskes R. (1993.a) Failed innovation in total hip replacement, Acta Orthop. Scand. 64, 6, 699-716.

10. Huiskes R. (1993.b) Mechanical failure of total hip arthroplasty with cement, Curr. Orthop. 7, 239-247.

11. Jasty J.M., Floyd W.E., Schiller A.I., Goldring S.R., and Harris W.H. (1986) Localized osteolysis in stable, non-septic total hip replacement, $J$. of Bone and Int. Surg., 68-A, 912-919.

12. Jasty M., Maloney W.J., Bragdon C.R., O'Conner D.O., Haire T., and Harris W.H. (1991) The initiation of failure in cemented femoral components of hip arthroplasties, $J$ Bone and Joint, 73b, 4, 551-558.

13. Krause W.R., Krug W., and Miller J.E. (182) Strength of the cement/bone interface, Clin Orthop., 163, 290-299.

14. Ling R.S.M. (1992) The use of a collar and precoating on cemented femoral stems is unnecessary and detrimental, Clin. Orthop., 285, 73-83.

15. Malchau H., Herberts P., Ahnfelt L., and Johnell O. (1993) Prognosis of total hip replacement, 61st AAOS, USA.

16. Verdonschot N., and Huiskes R. (1992) The application of continuum damage mechanics to pre-clinical testing of cemented hip prostheses: the effects of cement/stem debonding, In: Computer methods in biomechanics and biomedical engineering, J. Middleton eds., Walters,Son \& Co., Ltd., 50-57, Swansea.

17. Verdonschot N., and Huiskes R. (1994) The creep behavior of hand-mixed Simplex $\mathrm{P}$ bone cement under cyclic tensile loading, J Appl. Biomat., Vol. 5, 235-243. 